REVIEW

\title{
Revisiting the $A B C$ strategy: HIV prevention in Uganda in the era of antiretroviral therapy
}

\author{
S Okware, J Kinsman, S Onyango, A Opio, P Kaggwa
}

Postgrad Med J 2005;81:625-628. doi: 10.1136/pgmi.2005.032425

The ABC strategy is credited for bringing the HIV/AIDS epidemic under control in Uganda. By promoting abstinence, being faithful, and condom use, safe $(r)$ behaviours have been identified that are applicable to people in different circumstances. However, scaling-up of antiretroviral therapy in the country raised concerns that HIV prevention messages targeting the uninfected population are not taking sufficient account of inherent complexities. Furthermore, there is debate in the country over relative importance of abstinence in reduction of HIV incidence as well as over the morality and effectiveness of condoms. The purpose of this paper is to examine each component of $A B C$ in light of current developments. It is argued that there is still a strong justification for condom use to complement abstinence and being faithful. There is an urgent need to update and relaunch Uganda's $A B C$ strategy-its three elements are complementary, synergistic, and inseparable in the national HIV prevention programme.

See end of article for authors' affiliations

Correspondence to: Dr S Okware, Ministry of Health, PO Box 7272, Kampala, Uganda; okwares@yahoo.com

Submitted 13 January 2005 Accepted 12 March 2005
$\mathrm{T}$ he first cases of AIDS in Uganda were reported in 1982 from Rakai district in the south west of the country, an area bordering with the United Republic of Tanzania. The condition was popularly known as "Slim" disease, because of the extensive wasting that typically and classically characterises AIDS. Its spread was fuelled by a number of cultural and social factors including war and insecurity, poverty, traditional cultural norms, and the dominant role of men in sexual decision making.

Since the start of the epidemic, cumulatively more than two million people have been infected with HIV in Uganda (90\% through heterosexual activity), and about half of these have died, making it one of the most heavily affected countries in the world. The annual incidence of new AIDS cases is between 100000 and 120 000, and it is estimated that there were 70000 to 100000 new HIV infections nationwide in the year 2002 alone. $^{1}$ Ninety per cent of Uganda's population lives in under-served rural areas, which significantly complicates prevention, care, and mitigation activities.

However, Uganda can be cited in many respects as a success story with regard to HIV prevention and control. In 1986, President Yoweri Museveni directed the establishment of a National AIDS Control Programme (NACP), the first of its kind in Africa. This constituted the beginning of a national response to HIV/AIDS that was characterised by an environment of openness, strong political commitment, and support. The government promoted a process of active community mobilisation through civil society, school health programmes, cultural leaders, faith based organisations and, subsequently, employers.

NACP prevention activities have-in different ways at different times-been based on three main pillars, namely abstinence, being faithful, and condom use. (Nosocomial HIV infections via unsafe injections do occur in Uganda, ${ }^{23}$ but epidemiological evidence shows that sexual transmission is in fact by far the major mode of spread of HIV. ${ }^{4}$ ) Collectively, these three pillars have become known as the ABC strategy, and this approach has been adopted and implemented jointly by many partners. The trinity of interventions constitutes the minimum package required to contain the spread of HIV, with different groups emphasising different components. Religious leaders generally focus on A and $\mathrm{B}$, while civic and public mobilisers tend to promote all three approaches: A, B, and C. Strong political support-from the president down to local village councils- has been crucial to sustaining the $\mathrm{ABC}$ strategy, such that, at least in theory, every household in the country should have access to clear prevention messages.

Since the establishment of the NACP, a number of significant achievements have been reported, and these have been largely accredited to the $\mathrm{ABC}$ strategy. There has been a general decline in HIV seroprevalence among antenatal mothers at urban sites throughout the country, from about $30 \%$ in 1992 to $10 \%$ in $2002 .{ }^{1}$ The same trend has been seen in rural areas, with a decline from $14 \%$ to $5 \% .^{1}$ Furthermore, the prevalence of HIV among patients attending STI clinics has decreased from 45\% in 1990 to about $19 \%$ in $2002^{1}$; incidence rates in a general population cohort study in rural Masaka have also showed a decline from 7.6 to 3.2 per 1000 person years of observation ${ }^{5}$; and there has been a reported decline of over $60 \%$ of casual sex among 15-49 years, a significant indicator of behaviour change. In addition, the median age of sexual debut has increased from 14 years to 17 years. ${ }^{167}$

Against this background, the purpose of this paper is to briefly explore the particular characteristics of each of the three components of the

Abbreviations: $A B C$, abstinence, being faithful, condom use; ART, antiretroviral therapy 
$\mathrm{ABC}$ strategy, and also to put them into the context of current developments in AIDS control in Uganda. ABC has always been a dynamic and evolving strategy and the debate about it continues at community, national, and international levels. For instance, some governments and members of the international community focus strongly on abstinence for the youth, with condoms to be advocated only "as appropriate $^{\prime \prime} .{ }^{8}$

Meanwhile, there has been an enormous increase recently in the use of antiretroviral therapy (ART) for people living with HIV/AIDS in the country, and around 35000 Ugandans are now benefiting from these lifesaving drugs. This development will necessitate scaling up of preventive messages to counteract complacency, or "behavioural disinhibition", such as that which has been noted in some gay communities in the USA and Europe..$^{9-12}$ Such complacency could lead to AIDS being seen just like any other treatable chronic illness such as diabetes. A re-invigoration of the $\mathrm{ABC}$ strategy is therefore required as ARVs are rolled out throughout the country.

\section{UNPACKING THE ABC STRATEGY}

As stated above, the $A B C$ strategy has been credited with much of the success in Uganda's reduction in HIV incidence and prevalence. The three components are closely intertwined, complementing each other in much the same way that all the critical components of a car need to be in place for it to move. None is sufficient on its own and each has contributed to the larger success that is reflected in the form of demonstrable declines in HIV incidence and prevalence.

\section{Abstinence}

The term abstinence can refer either to a situation in which a young person who has never had sex delays starting sexual activity (primary abstinence), or to a person who decides to stop sexual activity after initiation (secondary abstinence).

While reliable data are unavailable to determine the impact of secondary abstinence on HIV transmission, there has been a strong focus on promoting primary abstinence for young people in Uganda through such innovative means as Straight Talk and Young Talk. These monthly sexual health newspapers target the youth, with print runs of 155000 and 280000 respectively; and the increase of the median age of sexual debut in the country from 14 to 17 years is indicative of the cumulative success of programmes such as these.

With a recent edition of Straight Talk devoted entirely to $\mathrm{ART},{ }^{13}$ there has been the recognition that the rapid influx of ART into Uganda has implications for young people. Therefore, programmes such as PIASCY (the Presidential Initiative on AIDS Strategy for Communication to Youth), the nationwide HIV/AIDS education programme for schools that was launched in mid-2004, ${ }^{14}$ should also be updated to take this into account and to develop appropriate messages that include ART.

Data from the Medical Research Council Programme on AIDS in rural Masaka suggest that the protective value of primary abstinence in relation to HIV can last up until the age of 19 (J Whitworth, personal communication). Within the 13-19 age group in this study, higher rates of HIV seroconversion were-as would be expected-associated with a lower median age at first sex. However, among 20-24 year olds, no difference was found in HIV seroincidence between those who had delayed age at first sex and those who had not. In this age group, younger age at first sex was associated with more casual partners and more condom use, but not with HIV infection itself: for those aged 20-24 years, it is current sexual behaviour that is important. Thus, for young people up to the age of 19 years, early age of sexual debut is clearly a risk factor for HIV infection; and, by contrast, primary abstinence is protective.

\section{Being faithful}

In its purest sense, the $\mathrm{B}$ of $\mathrm{ABC}$ entails practising sex with just one partner, in a long term or lifelong relationship such as marriage and only after determining that both partners are not infected with HIV. Shades of grey do exist, however, with, for example, polygamous marital relationships and also those who engage in serial monogamy.

Since the start of the AIDS epidemic, faith based organisations have excelled in preaching abstinence and the promotion of fidelity to their flocks. In relation to the latter, the concept of "zero grazing" was developed-this is an agricultural term that is immediately understood by anyone in this largely agrarian society, and which refers to feeding one's livestock exclusively within the paddock. The humorous double meaning that applies to HIV prevention maintains that one keeps to an exclusive and monogamous relationship, also "within the paddock". There is strong evidence that a large portion of the Ugandan population has taken up the practice of zero grazing, a phenomenon that has been described as being "equivalent to a highly effective vaccine" for HIV. ${ }^{15}$

Total fertility rates are currently estimated at 6.9 children per woman, ${ }^{16}$ scarcely down from the seven children per woman that was reported in the late 1980 s. ${ }^{6}$ This is evidence that women today are engaging in a similar number of unprotected sexual contacts as they did 15 years ago or so. Despite this, however, HIV prevalence and incidence have demonstrably fallen over the same period, and especially so among young women. ${ }^{5}$ The explanation lies in the suggestion that although these women are having roughly the same absolute number of sexual contacts as their older sisters and mothers used to, they may be having fewer sex partners-in other words, they are "being faithful". This interpretation is supported by data from two cross sectional demographic and health surveys, conducted in 1989 and 1995, which showed a reduction of $60 \%$ in respondents who reported having had sex with a "non-regular partner" during the previous 12 months. ${ }^{16}$ The trend continued, at least among unmarried women, until another survey, conducted in $2000 .^{6}$ Thus, zero grazing is a tried and tested strategy, and it should be firmly emphasised in a re-invigorated, comprehensive HIV prevention programme in the era of ART.

\section{Condoms}

When used consistently and correctly, the male condom is effective for the reduction of sexual transmission of HIV and of other sexually transmitted infections. ${ }^{18-20}$ However, the extent to which condoms have been embraced by the Ugandan public has fluctuated considerably over the years, and they have recently become the focus of an increasingly bitter public debate.

During the period immediately after the establishment of the NACP in 1986, condom promotion messages were limited to the dissemination of technical information about their role in prevention of STIs including HIV. Condom use was low during this period, because of limited publicity, low availability, and taboo-many people believed that they encouraged promiscuity. There was also considerable public resistance from some religious organisations, media groups, and political lobbies, who maintained that their moral values stood against the condom for personal, cultural, and ideological reasons. Furthermore, it was felt in some quarters that message clarity was compromised if people were asked to "Love Faithfully" while at the same time they were being encouraged to use condoms-this potentially would lead to conflicting messages. 
However, as the potential contribution of condoms was increasingly recognised by public health workers, the government adopted in 1991 a policy of "quiet promotion and responsible use of condoms with appropriate education". ${ }^{21}$ This formed the beginning of the comprehensive national ABC strategy. A condom policy and strategy has since evolved that effectively created a demand for condoms for the prevention of STIs, including HIV, through the establishment of a positive image for condom use. This nationwide programme has involved stakeholders from all sectors; government, health care workers, religious leaders, NGOs, academics, business community, and the private sectors. Condom uptake was immediate, which was greatest initially in the urban areas but later on even in the rural areas. The result has been that regular condom use with noncohabiting partners rose from 5\% in 1987 to over $60 \%$ in $2002^{16}$; and the procurement of condoms rose from 10 million in 1994 to 30 million in 1997 and then on to 120 million in 2003.

Discussions over the extent to which all these condoms have contributed to curbing Uganda's AIDS epidemic have sometimes revolved around ideology or conviction rather than evidence. ${ }^{22}$ It is clear, however, that national HIV prevalence began to fall in the late 1980s and early 1990s, ${ }^{53}$ several years before condoms were available in large numbers; and this means that much of the credit for turning the tide must go to the "home grown", community derived solutions to the problem: A and B..$^{22-24}$ None the less, regardless of the occasionally acrimonious arguments about the relative importance of condoms in Uganda, they should definitely continue to constitute a synergistic component of the national HIV prevention strategy within the context of ART. ${ }^{18}$ There are a number of categories of people for whom condoms will remain an absolute necessity:

(1) The number of people living with HIV and AIDS-and hence also national HIV prevalence-will rise considerably in the coming years as a result of the country's rapidly expanding ART programme. The proportion of these people who know that they are infected will also increase, because of improving access to HIV voluntary counselling and testing. All of these infected people (about one million at present) must have easy access to condoms.

(2) A large proportion of HIV transmission is inadvertently taking place under "friendly fire" - that is, within mutually caring, monogamous relationships. As many as one third of all couples living with HIV are in fact discordant, with the negative spouse at very high risk of infection. In this regard, access to voluntary counselling and testing facilities must continue to improve to permit more people to make informed decisions about condom use.

(3) Activities of commercial sex workers are increasing in many urban areas in the country. A recent survey conducted on this group in Kampala reported an overall HIV prevalence among the respondents of $47 \%$, with a prevalence of $60 \%$ among those aged between 25-29 years. ${ }^{25}$

(4) In the 2000/2001 DHS survey, ${ }^{6} 17 \%$ of sexually active female respondents and $5 \%$ of male respondents reported having had an STI in the 12 months before the survey. Given the strong cofactor effect of STIs, correct and consistent use of condoms by STI patients and their partners is vital.

(5) A survey in Masaka district reported that about 4\% of married respondents admitted to having a regular partner of more than 12 months duration other than their spouses. In addition, $10 \%$ of sexually active married respondents reported that they had a non-regular partner defined as a short term relationship of less than 12 months. $^{7}$ These people, who are not adherent to either $\mathrm{A}$ or $\mathrm{B}$, need to receive regular supplies of condoms.

\section{DISCUSSION}

We stand at a critical moment in the history of the AIDS epidemic in Africa. The large scale political momentum to promote ART has significantly pushed forward efforts over the past two years to roll out treatment for people living with AIDS throughout the continent. The WHO's " 3 by 5" target may not be met in literal terms, but it has undeniably assisted in scaling up access to ART, and tens of thousands of people with AIDS are already benefiting as a result of the initiative. In Uganda alone, there are currently 35000 people taking ART from an estimated 120000 who are in need, an increase of $100 \%$ over the past 12 months.

There is a challenge in this, however: because of the current emphasis on treatment, a great deal of prevention effort is currently on those people who are known to be already infected, through the tailoring of appropriate prevention messages for patients taking ART regimens and their partners. Meanwhile, the hitherto sharp focus on the prevention needs of the uninfected population, as well as those who do not know that they are infected, is being lost.

We feel it is incumbent on all actors involved in fighting the AIDS epidemic in Africa to remember that while all due attention must of course be given to those already suffering from HIV related disease, the great majority of the population of every African country remains uninfected and therefore theoretically at risk. To ensure that they remain free of HIV, our efforts must be redoubled to identify and evaluate appropriate messages for this majority. Otherwise we face the calamitous prospect of increasing HIV prevalence (because of a decrease in AIDS related mortality because of ART), alongside an increase in HIV incidence (because of behavioural dis-inhibition within the general population). The long term burden to society of such a scenario would be intolerable.

Several reviews have concluded that each of A, B, and C have played a critical part in curbing the Ugandan AIDS epidemic to date, ${ }^{17} 2324$ with each of the three focusing on specific groups and behaviours, as identified in this piece; and it is evident that they should each continue to do so during the era of ART. A will continue to be an essential message for young people who have not yet become sexually active. $\mathrm{B}$ is imperative for all those persons who have established long term and life long relationships. "Zero grazing" is an attractive and engaging health promotion concept in this largely agricultural society, and as shown in this review, it has proved to be demonstrably effective. By failing to promote it sufficiently at this crucial moment, Uganda may return towards a more "free range" approach to loving, with undesirable consequences. Finally, C will remain vital for people living with HIV and for all those people who for one reason or another are not able to abstain or to be faithful to their partners. ${ }^{18}$

Abstinence, being faithful, and condom use are complementary, synergistic, and inseparable components in the country's HIV/AIDS national prevention and control programmes, and we need to roll out these prevention messages with extra urgency now, in the era of ART.

\section{ACKNOWLEDGEMENTS}

We thank Professor Jimmy Whitworth as well as the two anonymous referees for their valuable comments on the paper. 
Authors' affiliations

S Okware, S Onyango, A Opio, P Kaggwa, Ministry of Health,

Kampala, Uganda

J Kinsman, Amsterdam School for Social Science Research, University of Amsterdam, Netherlands

Funding: none.

Conflicts of interest: none.

\section{REFERENCES}

1 Republic of Uganda Ministry of Health. http://www.health.go.ug/docs/ hiv0603.pdf.

2 Brody S. Declining HIV rates in Uganda: due to cleaner needles, not abstinence or condoms. Int J STD AIDS 2004;15:440-1.

3 Gisselquist D, Potterat JJ, Brody S, et al. Let it be sexual: how health care transmission of AIDS in Africa was ignored. Int J STD AIDS 2003;14:148-61

4 Schmid GP, Buve A, Mugyenyi P, et al. Transmission of HIV-1 infection in subSaharan Africa and effect of elimination of unsafe injections. Lancet 2004:363:482-8

5 Mbulaiteye SM, Mahe C, Whitworth JA, et al. Declining HIV-1 incidence and associated prevalence over 10 years in a rural population in south-west Uganda: a cohort study. Lancet 2002;360:41-6.

6 Uganda Bureau of Statistics. The Uganda Demographic and Health Survey, 2000/2001. Entebbe: Uganda Bureau of Statistics, 2001.

7 STD/AIDS Control Programme, Ministry of Health. KABP and Sero-Survey on HIV/AIDS and STIs in Masaka District. Kampala: Ministry of Health, 2003.

8 Office of the United States Global AIDS Coordinator. The president's emergency plan for AIDS relief-US five-year global HIV/AIDS strategy. Washington, DC: 2004

9 Katz MH, Schwarcz SK, Kellogg TA, et al. Impact of highly active antiretroviral treatment on HIV seroincidence among men who have sex with men: San Francisco. Am J Public Health 2002;92:388-94.

10 Gremy I, Beltzer N. HIV risk and condom use in the adult heterosexual population in France between 1992 and 2001: return to the starting point? AIDS 2004; 18:805-9.
11 Scheer S, Chu PL, Klausner JD, et al. Effect of highly active antiretroviral therapy on diagnoses of sexually transmitted diseases in people with AIDS. Lancet $2001 ; 357: 432-5$

12 Boily MC, Bastos Fl, Desai K, et al. Changes in the transmission dynamics of the HIV epidemic after the wide-scale use of antiretroviral therapy could explain increases in sexually transmitted infections: results from mathematical models. Sex Transm Dis 2004;31:100-13.

13 Straight Talk Foundation. Straight Talk 2004;11:1-8.

14 Ministry of Education and Sports. PIASCY-helping pupils to stay safe; a handbook for teachers. Kampala: Ministry of Education and Sport, 2004.

15 Stoneburner RL, Low-Beer D. Population-level HIV declines and behavioural risk avoidance in Uganda. Science 2004;304:714-18.

16 Demographic and Health Surveys. http://www.cia.gov/cia/publications/ factbook/geos/ug.html.

17 Singh S, Darroch JE, Bankole A. A, B and C in Uganda: the roles of abstinence, monogamy and condom use in HIV decline. Washington, DC: The Alan Guttmacher Institute, 2003.

18 UNAIDS. Position statement on condoms and HIV prevention. Geneva: UN, 2004.

19 Holmes KK, Levine R, Weaver M. Effectiveness of condoms in preventing sexually transmitted infections. Bull WHO 2004:82:454-61.

20 Ahmed S, Lutalo T, Wawer M, et al. HIV Incidence and sexually transmitted disease prevalence associated with condom use: a population study in Rakai, Uganda. AIDS 2001;15:2171-9.

21 STD/AIDS Control Programme, Ministry of Health. National condom policy and strategy-draft. Kampala: Ministry of Health, 2003.

22 Green E. Rethinking AIDS prevention: learning from successes in developing countries. Westport, CT: Praeger, 2003.

23 Hogle JA. What happened in Uganda? Declining HIV prevalence, behavior change, and the national response. Washington, DC: USAID, 2002.

24 Population, Health and Nutrition Information Project. The 'ABCs' of HIV prevention: Report of a USAID technical meeting on behavior change approaches to primary prevention of HIV/AIDS. Washington, DC: USAID, 2002

25 STD/AIDS Control Programme, Ministry of Health. KABP and sero-survey on HIV/AIDS and STIs among commercial sex workers (CSWs) in Kampala City, Uganda. Kampala: Ministry of Health, 2003 